Table IV.

\begin{tabular}{|c|c|c|c|c|c|c|c|c|c|}
\hline$\hat{b} \backslash a$ & $1^{\mathrm{h}} .5$ & $4^{\mathrm{h}} \cdot 5$ & $7^{\mathrm{h}} .5$ & $10^{\mathrm{h}} .5$ & $13^{\mathrm{h}} \cdot \overline{5}$ & $16^{\mathrm{h}} \cdot 5$ & $19^{\mathrm{h}} . \tilde{5}$ & $22^{\mathrm{h}} . \tilde{\mathbf{z}}$ & Range \\
\hline+20 & +0.004 & -0.006 & -0.012 & $\begin{array}{l}\text { s } \\
+ \text { v.vojo }\end{array}$ & $-0.00 t$ & $\begin{array}{c}\mathrm{s} \\
+0.002\end{array}$ & +0.017 & -0.003 & 0.029 \\
\hline+15 & +0.016 & -0.005 & -0.018 & -0.004 & -0.006 & -0.008 & +0.015 & +0.007 & 0.034 \\
\hline+5 & -0.001 & +0.002 & -0.022 & -0.010 & -0.008 & +0.012 & +0.010 & +0.012 & 0.034 \\
\hline-5 & +0.004 & -0.003 & -0.020 & -0.010 & +0.002 & +0.014 & +0.004 & +0.012 & 0.034 \\
\hline$-1 \tilde{5}$ & 0.000 & +0.006 & -0.022 & -0.008 & -0.001 & +0.006 & +0.003 & +0.013 & 0.035 \\
\hline Mean & +0.005 & -0.001 & -0.019 & $-0.00 \tilde{5}$ & -0.003 & +0.005 & +0.010 & +0.008 & \\
\hline Formula & +0.007 & -0.004 & -0.013 & -0.010 & -0.002 & +0.004 & +0.008 & +0.010 & \\
\hline
\end{tabular}

$\Delta a=-0^{\mathrm{s}} .008 \sin a+0^{\mathrm{s}} .008 \cos a+0^{\mathrm{s}} .002 \sin 2 a+0^{\mathrm{s}} .002 \cos 2 \alpha$.

Another series of observations made from August, 1909, to April, 1911, on quite a different plan, as far as they give any information on this subject, confirm the results of the series just discussed. Two groups of six stars each, about 12 hours apart, the one in 6 hours right ascension and the other in 18 hours, were observed continuously during the period named, except the group that transited within two or three hours of the Sun. These groups transit at 6 A.M. and 6 P.M., at the equinoxes; and from 729 observations at four sucessive equinoxes, the mean correction to Newcomb was found to be 0 s.029 greater for the 18-hour group, than for the 6-hour group. From the individual corrections for these 12 stars, as found in the clock list of 277 stars, the mean correction for the

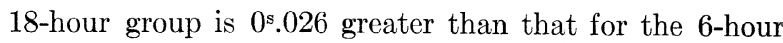
group.

The subject of the periodic error in the right ascensions of the fundamental catalogue has been treated by several writers recently. In Astronomische Nachrichten, No. 4668, from a discussion of Cape, Greenwich, Pulkowa and Odessa observations, CoHN finds the periodic correction to Auwers right ascension to be

$\Delta a=-0^{\mathrm{s}} .007 \sin a+0^{\mathrm{s}} .007 \cos a+0^{\mathrm{s}} .001 \sin 2 a+0^{\mathrm{s}} .006 \cos 2 a$. And in the Year Book, 1912, of the Carnegie Institution of Washington, p. 168, from the San Luis observations, Boss gives the periodic correction to his Preliminary General Catalogue as

$$
\Delta a=-0^{\mathrm{8}} .008 \sin a+0^{\mathrm{8}} .009 \cos a .
$$

\title{
OBITUARY NOTE.
}

The Astronomical Journal announces with sorrow the death of an Associate Editor, George William Hill. Doctor Hill died at his home in West Nyack, N. Y., on April 16, 1914. At the request of the Editor, Dr. R. S. Woodward has prepared a sketch of HiLL's life which arrived too late to be incorporated in the present issue. It will appear in the next number.

\section{NOTES.}

Correction to observation of Comet $1911(f)$ (OPIEnisset), published in Astronomical Journal No. 653:

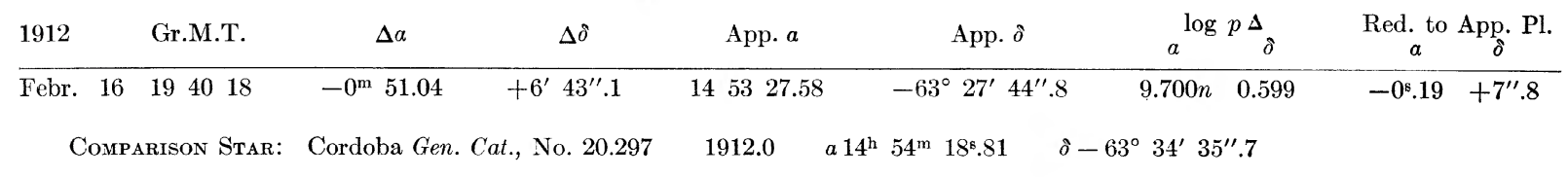

\section{CON T E N T S}

The Moon's Mean Longitude, 1908-13, and the Eclipse of August 21, 1914, by Frank E. Ross. The Period of o Persei, by Frank C. Jordan.

Errors in the Right Ascensions of Newcomb's Catalogue by W. S. Eichelberger and H. R. Morgan. OBITUARY Note.

Notes.

Acting Editor, Benjamin Boss, Albany, N. Y.; Associate kditor: Prof. Ernest W. Brown, of Yale University. Published by the Dudley

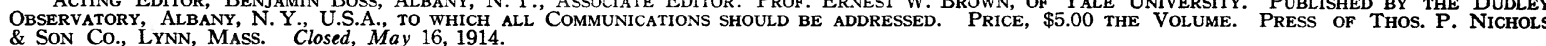

